\title{
Effect of Different Variables on the Size Distribution of Barium Chromate Nanoparticles
}

\author{
Mehdi Simiari $^{1,2}$, Mehrdad Manteghian ${ }^{1} \&$ Malihe Ghashamshmi-Iraj. ${ }^{3}$ \\ ${ }^{1}$ Materials Engineering Department, Faculty of Engineering, Tarbiat Modares University, Tehran, Iran \\ ${ }^{2}$ Department of Physics and Chemistry, Faculty of Science, Emam Ali University, Tehran, Iran \\ ${ }^{3}$ Department of Manufacturing Technologies, Malek-Ashtar University of Technology, ShahinShahr, Iran \\ Correspondence: Mehrdad Manteghian, Materials Engineering Department, Faculty of Engineering, Tarbiat \\ Modares University, Tehran, Iran. E-mail: manteghi@modares.ac.ir
}

Received: September 15, 2016

Accepted: September 28, 2016 Online Published: December 7, 2016

doi:10.5539/mas.v11n3p32

URL: http://dx.doi.org/10.5539/mas.v11n3p32

\begin{abstract}
In this study, the synthesis of $\mathrm{BaCrO}_{4}$ nanoparticles is performed by the reaction between $\mathrm{Ba}\left(\mathrm{NO}_{3}\right)_{2}$ and $\left(\mathrm{NH}_{4}\right)_{2} \mathrm{CrO}_{4}$ in the presence of surfactant. Different analyses such as X-ray diffraction (XRD), Transmission electron microscopy (TEM), Dynamic light scattering (DLS), and Energy Dispersive X-ray analysis (EDAX) are carried out to identify the features of nanoparticles. The tests are conducted in different concentrations of reactants and surfactants, and at the end, the results are compared. Optimum concentration is also measured and reported to achieve smaller nanoparticles. The results indicate that, in the synthesis of $\mathrm{BaCrO}_{4}$ nanoparticles, the best performance belongs to Sodium Citrate.
\end{abstract}

Keywords: barium chromate, nanoparticles, surfactant, sodium citrate, size distribution

\section{Introduction}

Precipitation from a solution is one of the methods of nanoparticle synthesis. In this process, a supersaturated solution is made followed by nucleation and nanoparticle formation ${ }^{1-3}$. The shape and size of nanoparticles depend on the conditions pertained during the synthesis, including supersaturation level, temperature, $\mathrm{pH}$ and nature of the solvent ${ }^{4,5}$. Stabilizers have been used to prevent the agglomeration of nanoparticles. The nature and concentration of stabilizers are varied to control the size and morphology of nanoparticles ${ }^{3-8}$.

Crystalline barium chromate $\left(\mathrm{BaCrO}_{4}\right)$ is known as an oxidant ${ }^{9}$. Considering the increase of the surface area of nano-sized materials, it is expected that nano-sized materials could increase the oxidation rate. $\mathrm{BaCrO}_{4}$ nanoparticles are synthesized by two methods: eggshell membrane or precipitation ${ }^{10-12}$. In the first method, the outer shell of an eggshell is used to filter and separate the nanoparticles from larger particles. In precipitation method, stabilizers prevent the agglomeration of nanoparticles. Guangjun Zhou et al. synthesized 4-6 nm $\mathrm{BaCrO}_{4}$ nanoparticles in the presence of an anionic surfactant by reaction between the aqueous solutions of $\mathrm{Ba}\left(\mathrm{NO}_{3}\right)_{2}$ and sodium chromate $\left(\mathrm{Na}_{2} \mathrm{CrO}_{4}\right)^{12}$.

In this research dodecylbenzene sulfonic acid sodium salt (DBSS), sodium citrate dihydrate $\left(\mathrm{Na}_{3} \mathrm{C}_{6} \mathrm{H}_{5} \mathrm{O}_{7} \cdot 2 \mathrm{H}_{2} \mathrm{O}\right)$, and polyvinylpyrolidone (PVP) to choose the best stabilizer were used in synthesizing $\mathrm{BaCrO}_{4}$ nanoparti cles. In order to optimize the parameters of synthesis of nanoparticles including the concentration of $\left(\mathrm{Ba}\left(\mathrm{NO}_{3}\right)_{2}\right.$ and $\left(\mathrm{NH}_{4}\right)_{2} \mathrm{CrO}_{4}$, and the type and concentration of stabilizer, the formed nanoparticles' features were identified and analyzed. Finally, the best parameters with the smallest size were reported.

\section{Method}

Different analyses such as X-Ray Diffraction (XRD), Transmission Electron Microscopy (TEM), Dynamic Light Scattering (DLS), and Energy Dispersive X-Ray (EDX) were carried out to characterize the nanoparticles. $\mathrm{BaCrO}_{4}$ nanoparticles were synthesized by the reaction between $\mathrm{Ba}\left(\mathrm{NO}_{3}\right)_{2}$ and $\left(\mathrm{NH}_{4}\right)_{2} \mathrm{CrO}_{4}$ in the presence of surfactant.

\subsection{Experimental}

In a typical experiment, $0.9125 \mathrm{~g}\left(\mathrm{NH}_{4}\right)_{2} \mathrm{CrO}_{4}$ and $4.4115 \mathrm{~g} \mathrm{Na}_{3} \mathrm{C}_{6} \mathrm{H}_{5} \mathrm{O}_{7} \cdot 2 \mathrm{H}_{2} \mathrm{O}$ were dissolved in $100 \mathrm{ml}$ distilled water in the main container. The solution was stirred for $2 \mathrm{hr}$ at $500 \mathrm{rpm}$ at room temperature. Then $0.4900 \mathrm{~g}$ 
$\mathrm{Ba}\left(\mathrm{NO}_{3}\right)_{2}$ was dissolved in $25 \mathrm{ml}$ distilled water, and stirred for $30 \mathrm{~min} .20 \mathrm{ml}$ of $\mathrm{Ba}\left(\mathrm{NO}_{3}\right)_{2}$ solution was added dropwise to the main container for $20 \mathrm{~min}$ under continuous stirring. Then, in order to form $\mathrm{BaCrO}_{4}$ nanoparticles, the solution was stirred for $36 \mathrm{hr}$. Some yellow precipitates were produced, and the solution was centrifuged for $45 \mathrm{~min}$ (at $3 \mathrm{steps}$, each $15 \mathrm{~min}$ ) at $10000 \mathrm{rpm}$. Product separated by centrifugation and then all precipitates along with ethanol and distilled water were washed to remove the impurities, ammonium nitrate and residual surfactants. The washed precipitates were dried in an oven at $150^{\circ} \mathrm{C}$ for $2 \mathrm{hr}$. The experiments were conducted at different concentrations of reactants and stabilizers are as shown in Table 1.

Table 1. Conditions of experiments

\begin{tabular}{ccccc}
\hline Run $\begin{array}{c}\text { Concentration of } \mathrm{Ba}\left(\mathrm{NO}_{3}\right)_{2} \text { Concentration of }\left(\mathrm{NH}_{4}\right)_{2} \mathrm{CrO}_{4} \\
(\mathrm{M})\end{array}$ & $(\mathrm{M})$ & ${ }_{\text {Type of surfactant }}$ Concentration of surfactant \\
& 0.075 & 0.12 & $\mathrm{Na}_{3} \mathrm{C}_{6} \mathrm{H}_{5} \mathrm{O}_{7} \cdot 2 \mathrm{H}_{2} \mathrm{O}$ & 0.3 \\
\hline 1 & 0.3 & 0.1 & $\mathrm{Na}_{3} \mathrm{C}_{6} \mathrm{H}_{5} \mathrm{O}_{7} \cdot 2 \mathrm{H}_{2} \mathrm{O}$ & 0.01 \\
2 & 0.1875 & 0.03 & $\mathrm{Na}_{3} \mathrm{C}_{6} \mathrm{H}_{5} \mathrm{O}_{7} \cdot 2 \mathrm{H}_{2} \mathrm{O}$ & 0.1 \\
3 & 0.1875 & 0.12 & $\mathrm{PVP}$ & 0.01 \\
4 & 0.075 & 0.1 & $\mathrm{PVP}$ & 0.1 \\
5 & 0.3 & 0.03 & PVP & 0.3 \\
6 & 0.1875 & 0.1 & DDBS & 0.3 \\
7 & 0.075 & 0.03 & DDBS & 0.01 \\
8 & 0.3 & 0.12 & DDBS & 0.1 \\
9 & & & & \\
\hline
\end{tabular}

Different experiments were conducted to identify and analyze the features of the formed nanoparticles: X-Ray Diffraction (XRD) was conducted to perform phase analysis. Transmission Electron Microscopy (TEM) was used to study the shape and size of the formed particles. Particle size distribution was studied by Dynamic Light Scattering (DLS), spectrophotometry and Energy Dispersive X-Ray (EDX) analysis were performed.

\section{Results and Discussion}

The reaction of $\mathrm{Ba}\left(\mathrm{NO}_{3}\right)_{2}$ and $\left(\mathrm{NH}_{4}\right)_{2} \mathrm{CrO}_{4}$ proceed as follows:

$$
\mathrm{Ba}\left(\mathrm{NO}_{3}\right)_{2(a q)}+\left(\mathrm{NH}_{4}\right)_{2} \mathrm{CrO}_{4(a q)} \rightarrow \mathrm{BaCrO}_{4(s)}+2 \mathrm{NH}_{4} \mathrm{NO}_{3(a q)}
$$

The results of XRD analysis (Fig. 1) showed that the solid phase product is $\mathrm{BaCrO}_{4}$ as nanoparticles in the space group Pnma (JCPDS file number 35-0642) [11]. EDX indicated that the produced particles are made of barium, chromium and oxygen (Fig. 2).

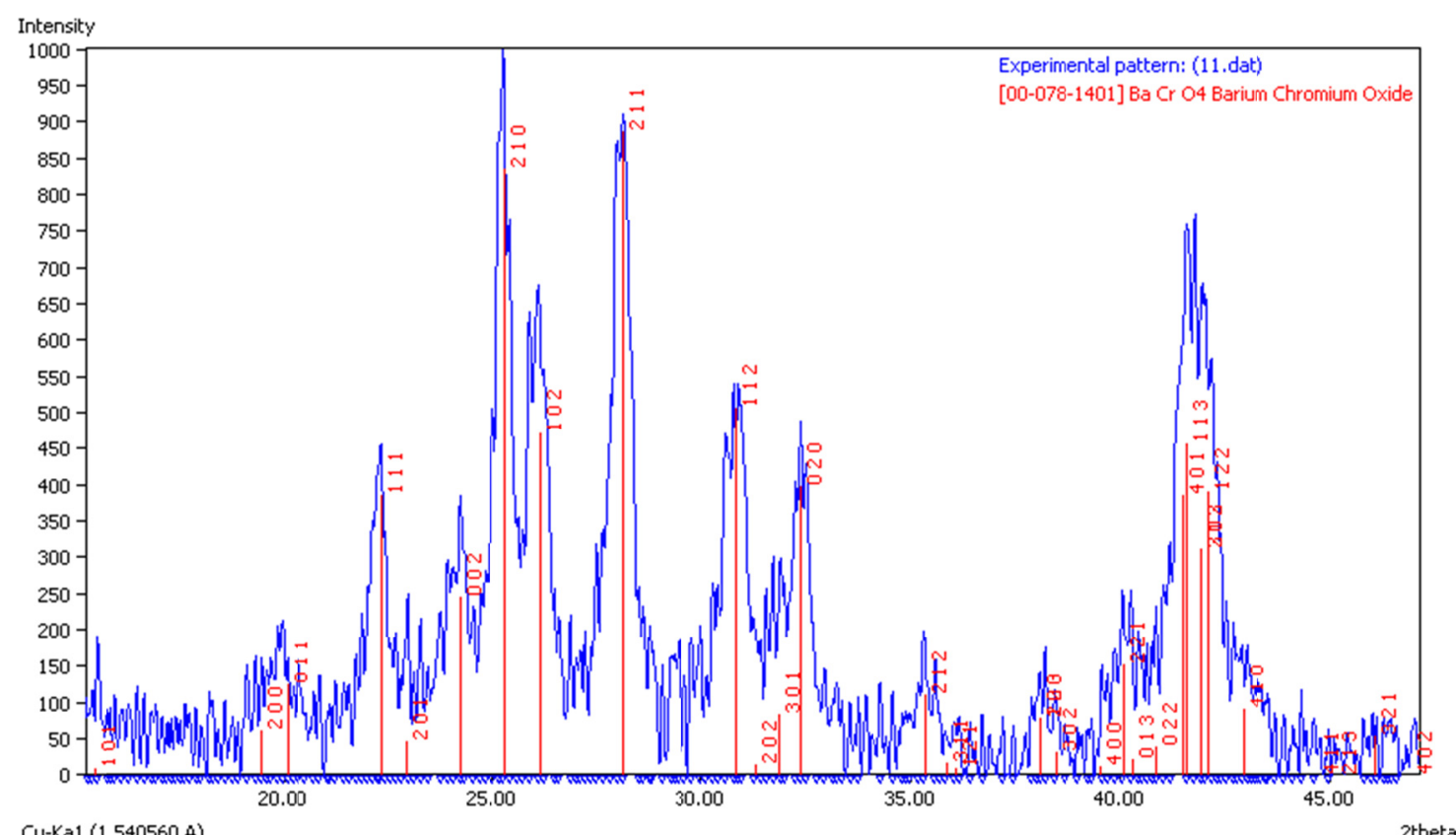

Figure 1. XRD spectrum of $\mathrm{BaCrO}_{4}$ nanoparticles 


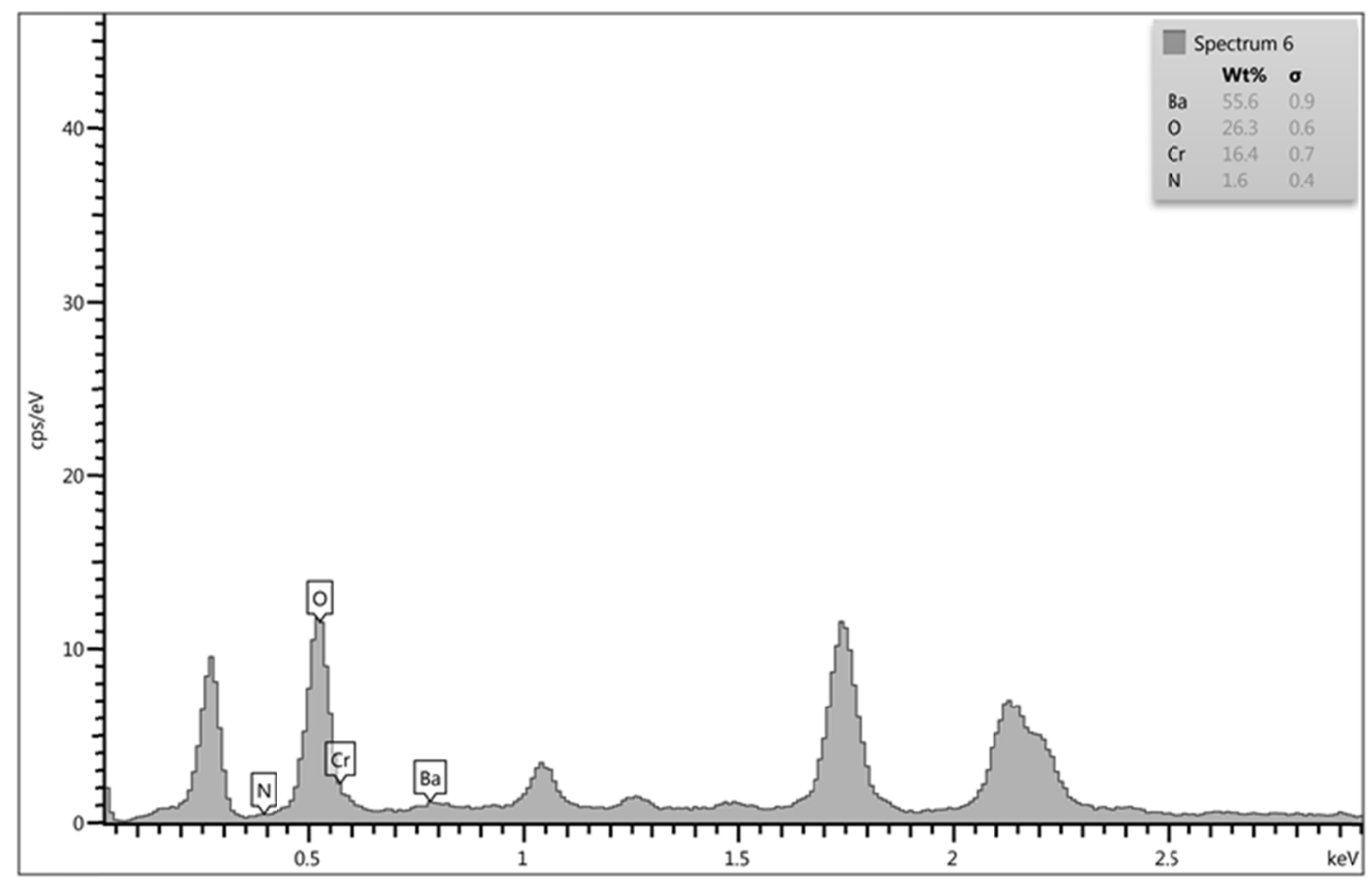

Figure 2. EDX spectrum of the product

UV-vis spectroscopy was performed in the wavelength range of 190-700 $\mathrm{nm}$. The results revealed that the absorption peak occurred in the wavelength of $375 \mathrm{~nm}$, complying with the reported peak of previous researches for $\mathrm{BaCrO}_{4}$ nanoparticles ${ }^{9,12}$ (Fig. 3).

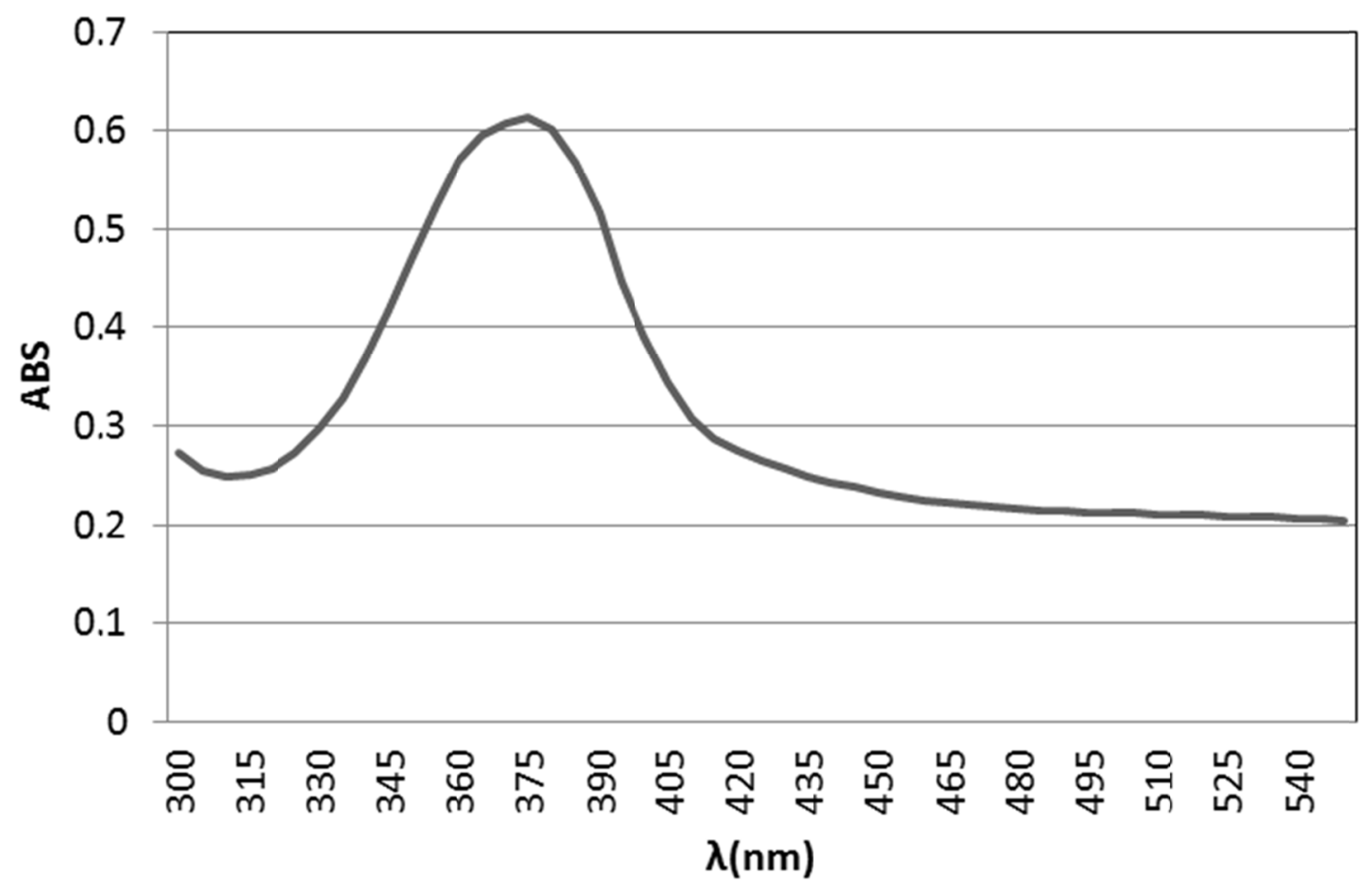

Figure 3. Absorption peak of $\mathrm{BaCrO}_{4}$ in UV-vis analysis 
TEM represents the shape of nanoparticles. The result shows that uniform nanoparticles have been formed in this study (Fig. 4). With regard to the effect of reactants' and surfactants' concentration on the nanoparticles' size, the experiments were conducted at different concentrations of reactants and stabilizers to optimize the experimental conditions. For this purpose, an experimental design procedure was followed. Variables are shown in Table 1. All samples were tested by DLS analysis to determine the size of formed particles (Fig. 5). As Table 2 depicts, increasing the $\left(\mathrm{NH}_{4}\right)_{2} \mathrm{CrO}_{4}$ concentration leads to the reduction of the formed particles. The smaller size of the particles obtained at higher concentrations of $\left(\mathrm{NH}_{4}\right)_{2} \mathrm{CrO}_{4}$ may be attributed to the high initial supersaturation of $\mathrm{BaCrO}_{4}$ in the solution that, in turn, increases the nucleation rate. In fact, the high level of supersaturation causes fast nucleation, and newborn particles do not grow. On the other hand, smaller nanoparticles are formed at lower concentrations of $\mathrm{Ba}\left(\mathrm{NO}_{3}\right)_{2}$. Drop-wise addition of $\mathrm{Ba}\left(\mathrm{NO}_{3}\right)_{2}$ causes a fast reaction; as a result, clusters do not have enough time to reach a critical size, and thus previously formed particles grow and the size of particles increases. Comparison of the presence of DBSS, $\mathrm{Na}_{3} \mathrm{C}_{6} \mathrm{H}_{5} \mathrm{O}_{7} \cdot 2 \mathrm{H}_{2} \mathrm{O}$ and PVP as the stabilizers with equal concentrations shows that smaller particles are formed in the presence of $\mathrm{Na}_{3} \mathrm{C}_{6} \mathrm{H}_{5} \mathrm{O}_{7} \cdot 2 \mathrm{H}_{2} \mathrm{O}$. This can be explained by better dissolving of $\mathrm{Na}_{3} \mathrm{C}_{6} \mathrm{H}_{5} \mathrm{O}_{7} \cdot 2 \mathrm{H}_{2} \mathrm{O}$ in water, allowing more additive be added to the system, and better coverage of nanoparticles by the surfactant. $\mathrm{Na}_{3} \mathrm{C}_{6} \mathrm{H}_{5} \mathrm{O}_{7} \cdot 2 \mathrm{H}_{2} \mathrm{O}$ will prevent nanoparticles from agglomeration by its good distribution in the solution and forming a covering film on the $\mathrm{BaCrO}_{4}$ nanoparticles. Furthermore, it was observed that the nanoparticles obtained when larger amounts of surfactant were used have a smaller size. It is concluded that at high concentrations, more surfactant molecules surround the nanoparticles, and the surfactant will stabilize the nanoparticles much more efficiently.

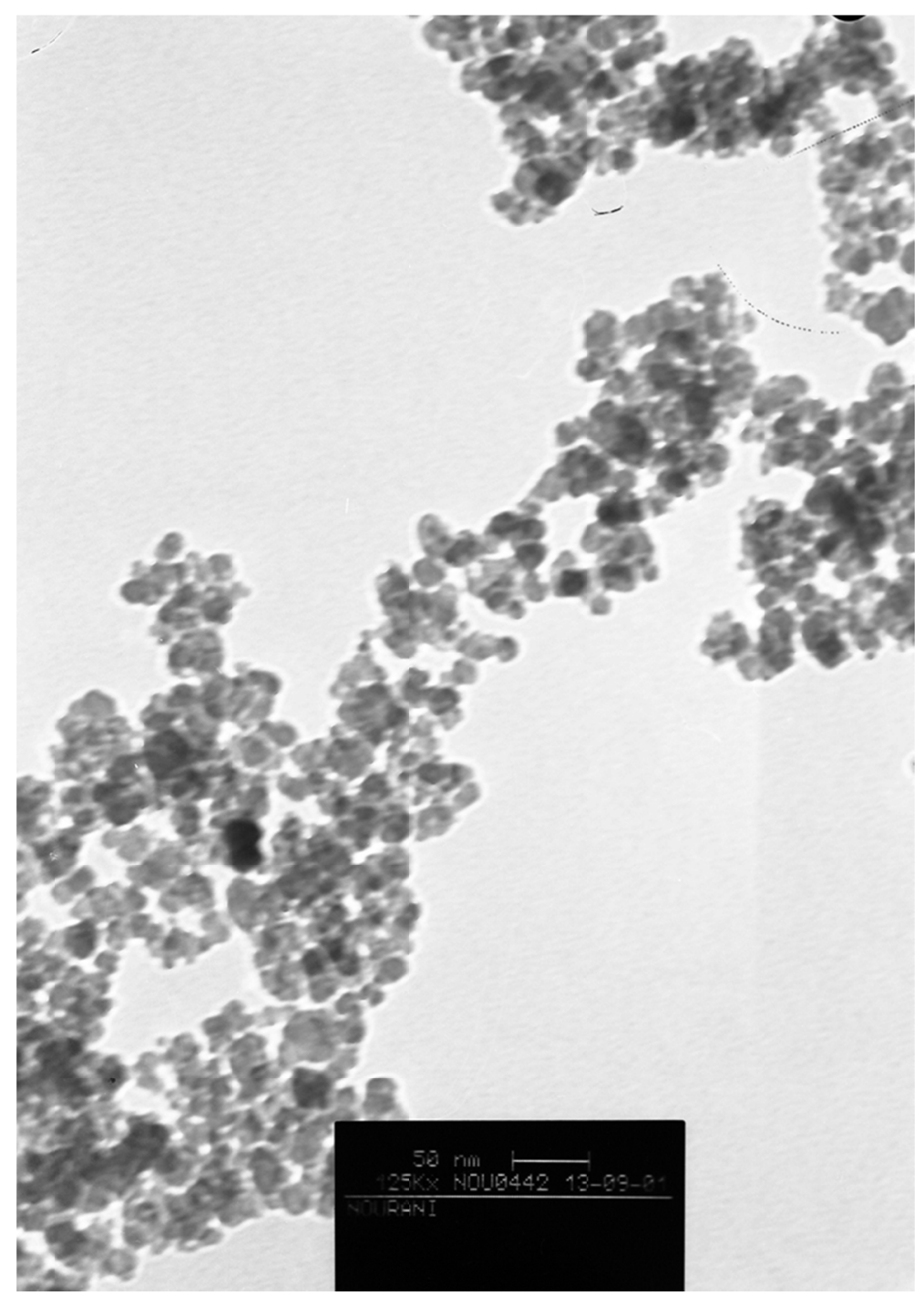

Figure 4. TEM image of $\mathrm{BaCrO}_{4}$ nanoparticles 


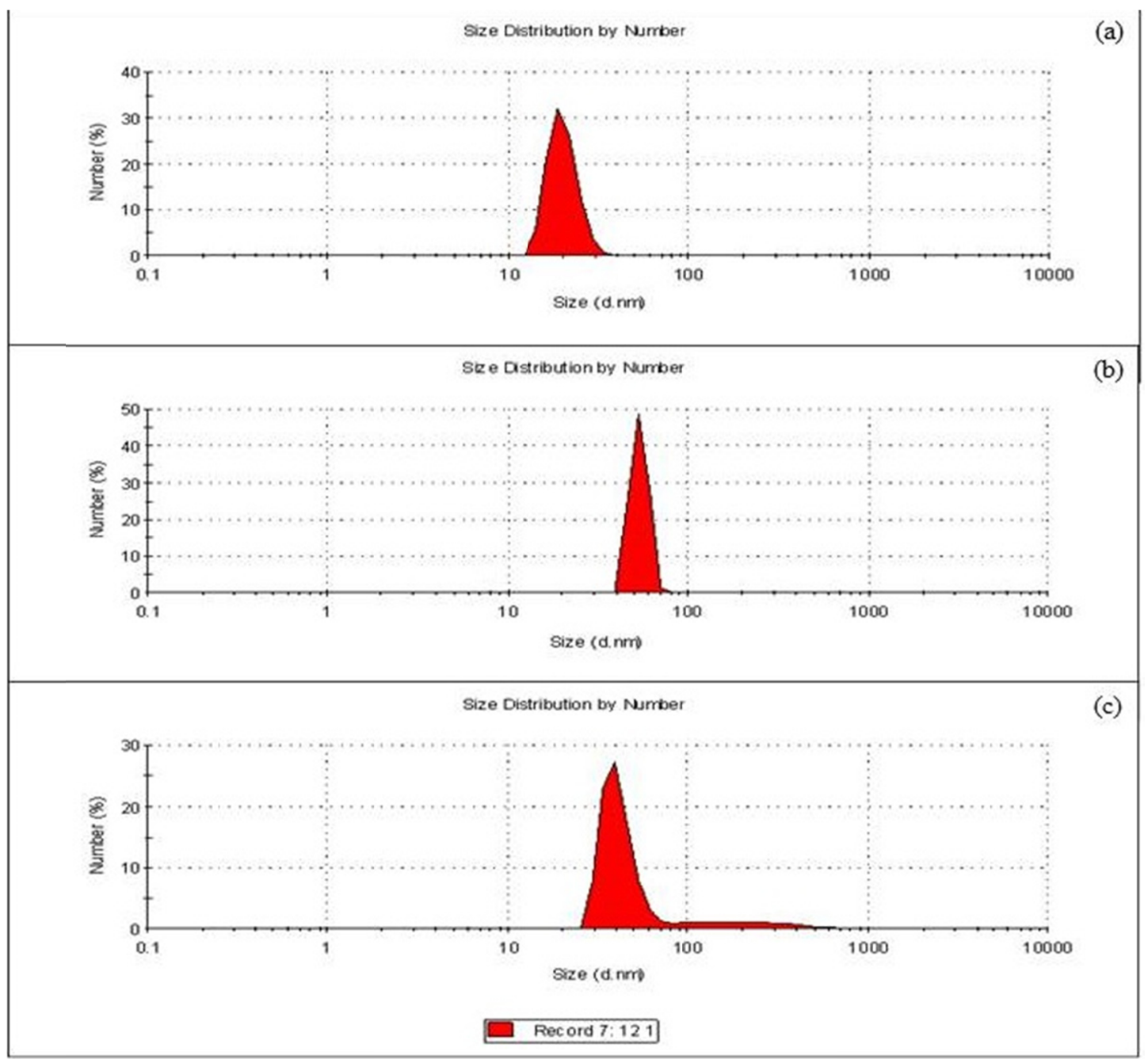

Figure 5. DLS analysis curves of the $\mathrm{BaCrO}_{4}$ nanoparticles obtained from different experiments: (a) Run 1, (b) Run 3, and (c) Run 2

Table 2. Effect of concentrations on the size of nanoparticles

\begin{tabular}{cccc}
\hline \multicolumn{3}{l}{ Run pH of solution $\begin{array}{c}\text { Size of particles } \\
(\mathrm{nm})\end{array}$} & Mean size of particles (nm) \\
\hline 1 & 7 & $12-35$ & 25 \\
2 & 8 & $25-500$ & 290 \\
3 & 8 & $30-170$ & 80 \\
4 & 7 & $50-265$ & 111 \\
5 & 7 & $14-50$ & 38 \\
6 & 7 & $34-170$ & 79 \\
7 & 11 & $39-180$ & 95 \\
8 & 10 & $80-470$ & 217 \\
9 & 11 & $52-270$ & 150 \\
\hline
\end{tabular}

The tests were conducted with different concentrations of reactants and surfactants, and the results were compared. It was revealed that, in the synthesis of $\mathrm{BaCrO}_{4}$ nanoparticles, sodium citrate acts as a more effective nanoparticle stabilizer.

\section{Conclusion}

In this paper, $\mathrm{BaCrO}_{4}$ nanoparticles were synthesized at different concentrations of $\mathrm{Ba}\left(\mathrm{NO}_{3}\right)_{2}$ and $\left(\mathrm{NH}_{4}\right)_{2} \mathrm{CrO}_{4}$ and surfactants. The DLS and TEM results showed that, in $\mathrm{BaCrO} 4$ nanoparticles synthesis, increasing the 
concentration of $\left(\mathrm{NH}_{4}\right)_{2} \mathrm{CrO}_{4}$ and surfactant will decrease the nanoparticles' size. Furthermore, smaller particles of $\mathrm{BaCrO}_{4}$ are formed in the presence of $\mathrm{Na}_{3} \mathrm{C}_{6} \mathrm{H}_{5} \mathrm{O}_{7} \cdot 2 \mathrm{H}_{2} \mathrm{O}$ as a stabilizer. Using $\left(\mathrm{NH}_{4}\right)_{2} \mathrm{CrO}_{4}$ to produce $\mathrm{BaCrO}_{4}$ nanoparticles has been performed for the first time in this research. The XRD and EDX analyses confirmed that the method yields a pure product.

\section{References}

Chaudhuri, R. G., \& Paria, S. (2010). Synthesis of sulfur nanoparticles in aqueous surfactant solutions. J. Colloid Interface Sci., 343(2), 439-46. http://dx.doi.org/10.1016/j.jcis.2009.12.004

Cho, Y. S., \& Huh, Y. D. (2011). Synthesis of three-dimensional hierarchical BaCrO 4 dendrites. Mater. Lett., 65(23), 3618-3620. http://dx.doi.org/10.1016/j.matlet.2011.07.055

El-Sheikh, S. M., El-Sherbiny, S., Barhoum, A., \& Deng, Y. (2013). Effects of cationic surfactant during the precipitation of calcium carbonate nano-particles on their size, morphology, and other characteristics. Colloids Surfaces A Physicochem. Eng. Asp., 422, 44-49. http://dx.doi.org/10.1016/j.colsurfa.2013.01.020

Gao, G. (2004). Nanostructures and nanomaterials: Synthesis, properties and applications. London: Imperial College Press. http://dx.doi.org/10.1021/ja0409457

Gawande, S. B., \& Thakare, S. R. (2013). Synthesis of visible light active graphene-modified $\mathrm{BaCrO}_{4}$ nanocomposite photocatalyst. International Nano. Lett., 3(37). http://dx.doi.org/10.1186/2228-5326-3-37

Ghader, S., Manteghian, M., Kokabi, M., \& Mamoory, R. S. (2007). Induction time of reaction crystallization of silver nanoparticles," Chem. Eng. Technol., 30(8), 1129-1133. http://dx.doi.org/10.1002/ceat.200700154

Husein, M., Rodil, E., \& Vera, J. H. (2004). Formation of silver bromide precipitate of nanoparticles in a single microemulsion utilizing the surfactant counterion. J. Colloid Interface Sci., 273(2), 426-34. http://dx.doi.org/10.1016/j.jcis.2004.02.057

Kohsari, I., \& Hajimirsadeghi, S. S. (2011). Application of the Taguchi method foroptimization experimental condition of synthesized Barium Chromate Nanoparticles by a precipitation method," Synth. React. Inorganic, Met. Nano-Metal Chem., 41(5), 465-471.

Kuwahara, T., Kohno, T., \& Wang, C. H. (2004). Static electric sensitivity characteristics of $\mathrm{Zr} / \mathrm{BaCrO} 4$ pyrolants," Propellants, Explos. Pyrotech., 29(1), 56-62. http://dx.doi.org/10.1002/prep.200400024

Liu, J. K., Wu, Q. S., \& Ding, Y. P. (2004). Assembling synthesis of Barium Chromate nano-superstructures using eggshell membrane as template. Bull Korean Chem Soc., 25, 1775-1778. http://dx.doi.org/10.5012/bkcs.2004.25.12.1775

Naseri, F., Irani, M., \& Dehkhodarajabi, M. (2016). Effect of graphene oxide nanosheets on the geotechnical properties of cemented silty soil. Archives of Civil and Mechanical Engineering, 16(4), 695-701.

Rahdar, A., Eivari, H. A., \& Sarhaddi, R. (2012). Study of structural and optical properties of ZnS: Cr nanoparticles synthesized by co-precipitation method. Indian Journal of Science and Technology, 5(1), $1855-1858$.

Takeno, N. (2005). Atlas of Eh-pH diagrams. Geol. Surv. Japan Open File Rep., 419, p. 102.

Tan, K. S. (2013). Advances of $\mathrm{Ag}, \mathrm{Cu}$, and $\mathrm{Ag}-\mathrm{Cu}$ alloy nanoparticles synthesized via chemical reduction route. J. Nanoparticle Res., 15(4), 1537. http://dx.doi.org/10.1007/s11051-013-1537-1

Zhou, G., Gu, F., Lü, M., Wang, S., Xiu, Z., Xu, D., \& Yuan, D. (2005). Synthesis and luminescence properties of $\mathrm{BaCrO}_{4}$ nanoparticles. Mater. Sci. Eng. B., 116(1), 71-74. http://dx.doi.org/10.1016/j.mseb.2004.09.012

\section{Copyrights}

Copyright for this article is retained by the author(s), with first publication rights granted to the journal.

This is an open-access article distributed under the terms and conditions of the Creative Commons Attribution license (http://creativecommons.org/licenses/by/4.0/). 